\title{
La formación del Derecho urbanístico chileno a partir del siglo XIX: de la legislación urbanística al Derecho urbanístico integrado
}

\author{
Eduardo Cordero Quinzacara*
}

\section{RESUMEN}

Esta investigación tiene por objeto determinar cómo ha surgido y se ha desarrollado el Derecho urbanistico en Chile, a partir de un conjunto de normas e instituciones que le otorgan una fisonomía especial que lo distinguen del Derecho común y de las técnicas de intervención propias de la policía administrativa. La tesis principal es que este fenómeno tiene lugar como consecuencia de los cambios sociales y económicos experimentados en la segunda mitad del siglo XIX, hasta conformar un sistema integrado a partir de 1929. Así, el autor distingue entre normas de incidencia urbanística y normas urbanísticas propiamente tales, ya sea en sentido amplio y estricto, que explican el origen, desarrollo y sentido actual del Derecho urbanístico chileno.

Urbanismo - legislación urbanística - evolución histórica

\section{The establishment of Chilean Urban Law from XIX Century: from Urban Legislation to Integrated Urban Law}

\begin{abstract}
This research aims to determine how has emerged and developed the Urban Law in Chile, based on a set of the rules and institutions that give a special appearance that distinguish the common law and the techniques from the administrative police intervention. The main thesis is that this phenomenon occurs as a result of social and economic changes experienced in the second half of the nineteenth century, to form an integrated system from 1929. So the author distinguishes between incidental urban regulations and urban regulation in the proper sense, whether in wide and strict sense, explaining the origin, development and current sense of the Chilean Urban Law.
\end{abstract}

Planning - urban law - historical development

* Abogado, Doctor en Derecho, Universidad Carlos III de Madrid. Profesor de Derecho Administrativo de la Pontificia Universidad Católica de Valparaíso. Correo electrónico: eduardo.cordero@ucv.cl.

Este trabajo es parte de una investigación financiada por FONDECYT referida al proyecto "La revisión de las bases dogmáticas del derecho urbanístico chileno. Propiedad, urbanismo y regulación de las actividades económicas" No 1130956.

Artículo recibido el 3 de octubre de 2015 y aceptado para su publicación el 1 de marzo de 2016. 


\section{INTRODUCCIÓN}

$\mathrm{E}$ ste trabajo tiene por objeto determinar cómo ha surgido y se ha desarrollado el Derecho urbanístico en Chile, a partir de las normas e instituciones que le otorgan una fisonomía especial que lo distinguen y desgajan de la concepción clásica del derecho de propiedad desde la perspectiva civil y de las técnicas de intervención propias de la policía administrativa.

Por su parte, las hipótesis que se tratarán de demostrar son las siguientes: a) Que existe un concepto amplio de norma urbanística, que comprende toda regulación que tiene por objeto la ordenación de los espacios urbanos, frente a un concepto estricto que se refiere a aquellas disposiciones que configuran al urbanismo como una función pública estatal con diversas técnicas de intervención y que culmina en lo que denominamos Derecho urbanístico en sentido estricto o integrado; b) Que el Derecho urbanístico en sentido estricto o integrado solo comienza a desarrollarse desde mediados del siglo XIX, con el cambio en la estructura económica y social que experimenta nuestro país, consolidándose a comienzos del siglo XX con las primeras leyes generales de urbanismo y construcciones, y c) Que los antecedentes directos del Derecho urbanístico integrado lo constituyen la regulación municipal por medio de la función de policía urbana y se consolida con un derecho legislado que no responde a una política permanente, sino que es una reacción frente a las nuevas contingencias sociales, sin perjuicio de que es posible encontrar en él algunas técnicas que son el origen de las instituciones básicas de esta disciplina.

Para el desarrollo de este trabajo y la demostración de cada una de estas hipótesis haremos una breve explicación del cambio en la estructura social y económica experimentada por nuestro país en el siglo XIX y que lleva a la dictación de diversas normas que regulan el fenómeno urbano, lo que nos permitirá distinguir entre normas de incidencia urbanística y normas urbanísticas en sentido amplio y estricto (II). Posteriormente vamos a centrar nuestra atención en los antecedentes del Derecho urbanístico actual, partiendo por la regulación municipal y el desarrollo de la policía urbana en este período (III); para dar paso a una legislación especial sujeta no solo a las contingencias propias del cambio social que se ha experimentado, sino también a algunas catástrofes que marcaron el desarrollo urbano de las ciudades (IV); culminando con un Derecho urbanístico integrado a partir de 1929, que comprende una legislación que enfrenta la cuestión urbana a partir de un sistema que abarca un conjunto de técnicas de intervención en el uso y gestión del suelo (V).

\section{URBANISMO Y DERECHO: NORMAS DE INCIDENCIA URBANÍSTICA Y NORMAS URBANÍSTICAS PROPIAMENTE TALES, EN SENTIDO AMPLIO Y ESTRICTO}

La relación entre el Urbanismo y el Derecho está marcada necesariamente por los cambios que ha experimentado nuestra sociedad en los últimos dos siglos. En efecto, si bien la historia da cuenta de diversas normas que se han dictado para regular los nuevos 
emplazamientos de las ciudades o las reformas de las ya existentes ${ }^{1}$, el actual Derecho urbanístico encuentra su sentido y fundamento en los fenómenos que comienzan a ocurrir en la segunda mitad del siglo XIX ${ }^{2}$, como consecuencia de las transformaciones experimentadas en la economía, la tecnología y la cultura que inciden necesariamente en la estructura de la sociedad, muchas de ellas impulsadas por una temprana industrialización ${ }^{3}$. Así, comenzarán a plantearse serios problemas en las viejas urbes coloniales a consecuencia de los incrementos demográficos, el déficit de vivienda, la carestía de los inquilinatos y, sobre todo, por razones higiénicas o de salubridad.

Ahora bien, este fenómeno debe ser comprendido desde una visión más amplia, especialmente por los cambios experimentados a partir de las nuevas ciudades industriales del siglo XIX que surgen en el mundo occidental. En este caso, el principal hito está marcado por la revolución industrial, iniciada en Gran Bretaña durante la segunda mitad del siglo XVIII. En el ámbito urbano aquello significó un gran desajuste entre el crecimiento de la población y el desarrollo urbano, pues sin ningún tipo de planificación ni orden la industria se apoderó del espacio urbano. A su vez, las ciudades industriales comenzaron a surgir rápidamente, acogiendo los barrios obreros donde se asentaría la mano de obra procedente de las zonas rurales, sin que existiera plan alguno para alojar las viviendas, las fábricas y las instalaciones necesarias para su funcionamiento. La única regla fue el aprovechamiento pleno del espacio disponible. Esto se traduce a su vez en viviendas pequeñas y familias hacinadas, que carecían de ventilación, luminosidad, agua

\footnotetext{
${ }^{1}$ Respecto de los antecedentes en el Derecho romano, se puede consultar Murga Genera, J. L., Protección a la estética en la legislación urbanística del alto imperio, Publicaciones de la Universidad de Sevilla, Sevilla, 1976, y Malave Osuna, M. B., Legislación urbanística en la Roma Imperial: a propósito de una constitución de Zenón, Servicio de Publicaciones e Intercambio Científico, Universidad de Málaga, Málaga, 2000. Sobre la influencia del Derecho romano y medieval también se puede ver Gómez Rojo, M. E., "Líneas históricas del Derecho urbanístico con especial referencia al de España hasta 1936", en Revista de estudios histórico-jurídicos, $\mathrm{N}^{\circ}$ 25, 2003. En el caso de Chile son muy importantes las normas dictadas bajo el período de la Colonia, especialmente aquellas contenidas en la Real Cédula de 1523 dada por el emperador Carlos V, la que fue recogida posteriormente en las Ordenanzas de descubrimiento, nuevas poblaciones y pacificaciones, dadas por Felipe II el 13 de julio de 1573. Este cuerpo normativo es incorporado en la Recopilación de Leyes de los Reinos de las Indias en su Libro IV, Título VII, Ley I, que trata De la población de Ciudades y Villas, y que dan forma a lo que se denomina el damero o cuadrícula tradicional propio de las ciudades coloniales. También son importantes los trabajos relativos a la política de fundación de ciudades de nueva planta del siglo XVIII, y que tuvieron por objeto crear núcleos urbanos que permitieran concentrar a la población dispersa en los campos. En este caso destacan los trabajos de Guarda O.S.B., G., Historia Urbana del Reino de Chile, Andrés Bello, Santiago, 1978; Lorenzo Schiaffino, S., Origen de las ciudades chilenas. Las fundaciones del siglo XVIII, Andrés Bello, Santiago, 1983, y del mismo Lorenzo Schiaffino, S. y Urbina Burgos, R., La política de poblaciones en Chile durante el siglo XVIII, El Observador, Quillota, 1978.

${ }^{2} \mathrm{G}$. Geisse lo describe muy bien al señalar que durante este período tres grandes acontecimientos históricos configuraron el contexto político-social dentro del cual se desarrollaron las ciudades hispanoamericanas: la ruptura del orden colonial a comienzos del siglo; la apertura de las economías nacionales a los mercados mundiales a mediados del siglo, y la penetración del capital extranjero junto con las doctrinas liberales a fines del siglo. Véase Geisse, G., "Tres momentos históricos en la ciudad hipanoamericana del siglo XX", en EURE, $\mathrm{N}^{\circ} 38,1986$, p. 7.

${ }^{3}$ Entre otros, Sabatini F. y Soler F., "Paradoja de la planificación urbana en Chile", en EURE, 63, 1995, pp. 62-63.
} 
potable y alcantarillado. En estas circunstancias, las ciudades industriales tenían las peores condiciones sanitarias posibles y altos índices de mortandad infantil ${ }^{4}$.

Si bien el caso de Chile es distinto, ya que se trata de una nación recién emancipada con una economía de tipo agraria, secundariamente comercial y con una industria inexistente, a partir de 1830 se comienza a experimentar un cambio importante, ya que se produce un incremento en la actividad minera mayor a la conocida en la época colonial, así como un aumento en la industria metalúrgica y naviera y, desde luego, una mayor actividad comercial y mercantil. Esto marcó el inicio de un cambio demográfico significativo constituido por el aumento de la población urbana y con ello todos los problemas asociados al crecimiento explosivo de las urbes ${ }^{5}$.

Así, a partir de estos nuevos problemas sociales se comenzaron a plantear -como ocurrió en los principales países europeos- diversas propuestas para enfrentar los requerimientos de vivienda y las cuestiones sanitarias derivadas de la necesidad de agua potable y sistemas de alcantarillado ${ }^{6}$. En primer término aquello se expresa en la dictación de varias disposiciones que hacen frente a esta cuestión a partir de la normativa municipal y las facultades de policía urbana, para posteriormente asumirla por medio de una legislación especial que lentamente llevará a un sistema integrado que formará parte de nuestra regulación urbanística y de la construcción ${ }^{7}$. Todo este conjunto de normas se sobrepondrá a la legislación existente dominada por los cánones civiles, especialmente respecto del concepto de propiedad.

Esta concurrencia de normas nos permite hacer una distinción de las diversas disposiciones que regulan la cuestión urbana. En efecto, en primer término nos encontramos con las normas que no siendo estrictamente urbanísticas, tienen incidencia en la materia, como ocurre con la legislación común, contenida fundamentalmente en el Código Civil chileno, que comenzará a regir en 1857, pero que es fruto de toda una tradición jurídica multisecular proveniente del Derecho común. Para nuestro análisis, este cuerpo normativo contiene normas de incidencia urbanística centradas en la regulación

${ }^{4}$ Estos hechos son conocidos y se encuentran documentados en diversos trabajos. Al respecto se puede consultar Benevolo L., Los orígenes del urbanismo moderno, Ecleste Ediciones, Madrid, 1996, y Sica P., Historia del urbanismo moderno. El siglo XX, Instituto de Administración Local, Madrid, 1981.

${ }^{5}$ A 1885 la población urbana chilena llegaba a 30,6\% sobre un total de 2.500 .700 habitantes. Diez años más tarde el porcentaje de chilenos en las ciudades subirá a 38\%. Las ciudades principales eran Santiago, con 250.000 habitantes y Valparaíso, con 120.000 habitantes. Véase Jans, S., El desarrollo de las ideas socialistas en Chile, Santiago, 1984, consultado en http://www.archivochile.com/Izquierda_chilena/vision_gen/ICHvisiongen0005. pdf; y Sunkel, O., Un siglo de Historia económica de Chile. 1830-1930, Ediciones Cultura Hispánica, Madrid, 1982, pp. 95-101.

${ }^{6}$ De Ramón, A., Santiago de Chile (1541-1991). Historia de una sociedad urbana, Editorial Sudamericana Chilena, Santiago, 2000, p. 146; De Ramón, A., "Santiago de Chile, 1850-1900. Límites urbanos y segregación espacial”, en Revista Paraguaya de Sociología, No 42-43, 1978, pp. 258-262; y Vicuña Mackenna, B., La transformación de Santiago, Imprenta de la Librería del Mercurio, Santiago, 1872, pp. 24-25.

${ }^{7}$ De Ramón, A., Santiago de Chile (1541-1991). Historia de una sociedad urbana, Editorial Sudamericana Chilena, Santiago, 2000, p. 146; De Ramón, A., "Santiago de Chile, 1850-1900. Límites urbanos y segregación espacial”, en Revista Paraguaya de Sociología, No 42-43, 1978, pp. 258-262; y Vicuña Mackenna, B., La transformación de Santiago, Imprenta de la Librería del Mercurio, Santiago, 1872, pp. 24-25. 
del derecho de propiedad, aunque sin la pretensión de ordenar el uso del suelo desde una perspectiva pública ${ }^{8}$.

En segundo término nos encontramos con la normativa urbanística propiamente dicha, que es aquella que tiene por objeto establecer una regulación en el uso y la edificabilidad del suelo. En un comienzo aquello se hace por razones religiosas, militares, para la fundación de ciudades de nueva planta o para limitar excepcionalmente el crecimiento descontrolado de las ciudades, hasta llegar a la formulación de una visión global del orden de la ciudad. A su vez, desde esta perspectiva podemos distinguir entre un concepto amplio de norma urbanística y un concepto estricto. En sentido amplio, las normas urbanísticas comprenden todas las disposiciones que se han dictado durante las diversas etapas de la historia de la humanidad para la creación y orden de la ciudad, y que han tenido cierta persistencia en la legislación actual (fundación de ciudades, espacios públicos, alturas de edificios, etc.). Por consiguiente, las normas urbanísticas propiamente dictadas o de Derecho urbanístico responden al fenómeno que se produce a partir de la segunda mitad del siglo XIX y que dan lugar a la existencia de una función pública específica, con instituciones propias, que buscan obtener un orden racional del espacio y la ciudad como respuesta a las necesidades sociales y económicas de una población urbana en crecimiento. Esta se caracteriza por el desarrollo de diversos instrumentos de intervención por parte de los órganos públicos, con el objeto de encauzar la relación del hombre con el suelo, estableciendo límites en su uso hasta llegar a formas más complejas de ordenación de todas las actividades que se desarrollan en este, y que denominaremos Derecho urbanístico integrado.

Siendo el objeto de este trabajo identificar y comprender los antecedentes históricos inmediatos que han determinado el actual régimen urbanístico de la propiedad en Chile, nos vamos a centrar en el análisis de la legislación urbanística que se origina en nuestro país a partir del siglo XIX. En este caso vamos a comenzar nuestra investigación con el Derecho urbanístico que surge a partir de la regulación municipal decimonónica, para luego tratar el Derecho urbanístico legislado a partir de 1874 y llegar al Derecho urbanístico integrado que se inicia en 1929.

\footnotetext{
${ }^{8}$ En este sentido, nuestro Código Civil contempla algunas normas de incidencia urbanística, muchas de ellas tomadas de las Siete Partidas de Alfonso X, y que regulan dos materias específicas: a) el resguardo de los bienes nacionales de uso público, es decir, aquel conjunto de bienes que integran el espacio público en la ciudad, como calles, plazas, puentes y playas, así como los bienes patrimoniales, como son los terrenos fiscales (Artículos 559, 600 y 601), y b) la regulación de servidumbres legales y de acciones posesorias (Artículos $842,844,855,856,875,878,930,931,932,937$ y 948). Sin embargo, solo se trata de disposiciones que giran en torno al concepto liberal y absoluto de propiedad, estableciendo apenas limitaciones al ejercicio de este derecho.
} 


\section{El Derecho urbanístico en el marco DE LA REGULACIÓN MUNICIPAL}

\section{La policía urbana y las ordenanzas municipales}

La policía urbana fue el título que por antonomasia justificaba las intervenciones de los Ayuntamientos durante el Antiguo Régimen que, respecto de los cometidos que tenían una relación directa con la seguridad, salubridad, comodidad y ornato de las poblaciones, permitía encauzar las cuestiones de esta naturaleza que suscitaban los asentamientos de las urbes preindustriales ${ }^{9}$. Si bien con el advenimiento del constitucionalismo se va a producir lo que se ha llamado el "desarbolamiento de la función de policía"10, se mantiene en poder de la Administración la facultad de limitar los derechos individuales -previa habilitación legal- mediante reglamentos administrativos y, especialmente, por las ordenanzas municipales. Estas fueron el principal instrumento de regulación de la construcción y el urbanismo, contenido típico de la "policía urbana" y de las relaciones vecinales de convivencia y orden ${ }^{11}$.

El urbanismo en esta época descansa, en definitiva, en la construcción o edificación privada -sobre todo porque la mayoría de los inmuebles están en manos de particulares-, sujeta a las ordenanzas de policía que imponen limitaciones en materias de uso y construcción de edificios, sin que esto implique una acción específica referida a la ciudad como tal, y menos aún una política de transformación del suelo destinada a la producción de nuevos espacios edificables. Por otra parte, los elementos colectivos o comunes necesarios para la edificación urbana son desarrollados de forma independiente bajo la forma de obra pública (caminos, calles, plazas, puentes, infraestructura sanitaria, etc.), que tiene como principal instrumento la expropiación. Esta etapa la podemos denominar urbanismo inicial o protourbanismo, propio del Estado liberal, que resulta de la suma de la reglamentación de la construcción privada y de la obra pública ligada a concretas necesidades colectivas o de interés común ${ }^{12}$.

${ }^{9}$ La "Novísima Recopilación” contiene innumerables disposiciones acerca de la materia, recogida en diversos títulos: reedificación de solares yermos (Ley VII, Título 19, Libro III), empedrados de calles (Ley II, Título 32, Libro VII), industrias insalubres (Ley V, Título 40, Libro VII), etc.

${ }^{10}$ En efecto, esta deja de ser una función que confiera un título cuasiuniversal para la acción pública, mutando hacia perfiles más nítidos y acordes con los principios del Estado liberal, fundamentalmente con el de legalidad de las actuaciones municipales y su vinculación al concepto de "orden público" en el esquema liberal imperante (tranquilidad, seguridad y salubridad pública). Véase Parejo, L., "Apuntes para una interpretación del sistema legal urbanístico en clave histórica”, en Ciudad y Territorio, Nº 107-108, 1996, p. 150.

${ }^{11}$ García de Enterría, E., "Dictamen sobre legalidad de ordenanzas municipales sobre el uso del suelo y edificación”, en Revista de Administración Pública, N 50, 1966, p. 312.

12 Parejo, L., "Apuntes para una interpretación del sistema legal urbanístico en clave histórica”, en Ciudad y Territorio, No 107-108, 1996, p. 151. 


\section{Las leyes de municipalidades y la policía urbana}

En Chile se dictaron diversas leyes en la segunda mitad del siglo XIX por las que se atribuían facultades a las municipalidades en materias urbanísticas vinculadas a las condiciones funcionales de la ciudad, así como en los aspectos sanitarios y de seguridad. De aquello dan muestras las Leyes sobre Organización y Atribuciones de las Municipalidades de 8 de noviembre de 1854 y de 12 de septiembre de 1887. Esta legislación coexistirá con las normas especiales que se dictarán para determinadas ciudades, para luego ser consolidadas en la legislación municipal de 1915.

La "Lei Sobre Organización i Atribuciones de las Municipalidades" de 8 de noviembre de 1854 constituye una de las primeras respuestas a los problemas urbanos. En ella se asignó a las municipalidades la responsabilidad en el cuidado de las condiciones funcionales, sanitarias y de seguridad de las entidades urbanas de su jurisdicción ${ }^{13}$. Esto comprende materias de policía general para garantizar el buen orden y tranquilidad de los vecinos; de policía de caminos, que incluía las calles; y de policía sanitaria ${ }^{14}$. Sin embargo, esta ley mantiene la debilidad municipal en el marco de un régimen liberal, que traspasa la solución de los problemas sociales y locales al ámbito privado ${ }^{15}$. Por su parte, la "Lei Sobre Organización i Atribuciones Municipales" de 12 de septiembre de 1887 no presenta mayores innovaciones en la materia, a pesar de ser una respuesta a los problemas sanitarios más graves que vivió nuestro país producto del colera morbus y que en su momento dio lugar a la dictación de la ley de 30 de diciembre de 1886, sobre Policía Sanitaria, y a la Ordenanza General de Salubridad, de 10 de enero de 1887.

Un avance más sustancial en encuentra en la Ley de Municipalidades de 1891, conocida como "Ley de la Comuna Autónoma", que integra las normas urbanísticas anteriores con nuevas potestades públicas. En este sentido, se introduce por primera vez la fijación de los límites urbanos de la ciudad y las condiciones en que podían entregarse al uso público nuevos barrios ${ }^{16}$, se reglamenta con mayor detenimiento la construcción de edificios u otras obras al costado de las vías públicas, determinando las alineaciones correspondientes y las condiciones de edificación para evitar la caída de los mismos ${ }^{17}$. Se debe mencionar, además, que desde 1886 se considera que el abastecimiento y evacuación de aguas o alcantarillado es un elemento obligatorio en toda propiedad urbana y, por tanto, de las obras de urbanización ${ }^{18}$.

${ }^{13}$ Gurovich W., A., "Conflictos y negociaciones: La Planificación Urbana en el desarrollo del Gran Santiago, Chile”, en Revista de Urbanismo, $\mathrm{N}^{\circ} 2,2000$, p. 5.

${ }^{14}$ Artículos $26 \mathrm{~N}^{\circ}$ 6; $27 \mathrm{~N}^{\circ}$ s. 3, 5 y 7; y 28.

${ }^{15}$ Salazar, G., "El Municipio Cercenado (La lucha por la autonomía de la asociación municipal en Chile, 1914-1973)”, en Salazar, G. y Benítez, J., Autonomía, espacio y gestión del municipio cercenado, Universidad Arcis, Santiago, 1998, pp. 5-60.

16 Artículo $25 \mathrm{~N}^{\mathrm{o}} 1$.

17 Artículo $25 \mathrm{~N}^{\circ} 10$.

${ }^{18}$ En 1886 se dicta la Ley $N^{\circ} 342$ de 16 de diciembre, en ella se establece un servicio obligatorio de desagües por medio de alcantarillas y cañerías, estableciendo como obligación de los propietarios de bienes raíces situados en barrios en que se coloquen alcantarillas el de conectarse a ellas, para lo que debían instalar 


\section{El INICIO DEL DEREChO URBANÍSTICO LEGISLAdO}

Para enfrentar los nuevos problemas del crecimiento urbano, y en paralelo a la legislación municipal, se dictaron diversas leyes que regularon de forma específica la transformación de las ciudades de Santiago (1874), Curicó (1875), Valparaíso (1876), Limache (1907), Talca (1909), Valdivia (1910) y Concepción (1912).

Es importante tener presente que estas legislaciones no se enmarcan en una política que responda a una planificación integral y respaldada por una legislación general, como sucedió con las políticas de fundación de ciudades del siglo XVIII ${ }^{19}$. En este caso nos encontramos ante disposiciones que son una reacción contingente y singular frente a la nueva realidad social y urbana que se produce en cada una de las ciudades, así como también ante las catástrofes que les tocó padecer, ya sean terremotos o incendios. En definitiva, no se trata de legislaciones con pretensiones de permanencia, aunque es posible encontrar en ellas el origen incipiente de algunas técnicas de intervención, aunque para algunos constituyen solo precedentes aislados del 30 del siglo pasado.

Atendido los límites de extensión de este trabajo, solo vamos a hacer una exposición cronológica, con la finalidad de destacar las principales innovaciones y las nuevas técnicas de regulación que se van introduciendo, hasta su consolidación en la legislación municipal de 1915 .

\section{Lei sobre apertura i prolongación de calles i paseos públicos en la ciudad de Santiago, de 25 de junio de 1874}

Esta ley se enmarca en una respuesta más amplia frente a los problemas que presentaba la ciudad de Santiago desde mediados del siglo XIX, producto del aumento de la población y un crecimiento descontrolado de la ciudad. La emigración de los campesinos a la capital implicó un aumento significativo de la pobreza y el surgimiento de barriadas en los márgenes del centro urbano, con varios problemas aparejados como la falta de higiene, la delincuencia, la mendicidad, etc. ${ }^{20}$ Frente a ello se adoptaron medidas muy concretas, como fue el Decreto de 24 de julio de 1843, por el que se estableció la obligación de colocar ventanas en las habitaciones, evitando los problemas de higiene que generaban los “cuartos redondos" ${ }^{21}$; se aprobó una Ordenanza Municipal sobre Rancherías, que

las cañerías y demás aparatos que el servicio de desagües requiriese a su propia costa, y permitir, además, el ingreso a su domicilio de los funcionarios encargados.

19 O.S.B., G., Historia Urbana del Reino de Chile, Andrés Bello, Santiago, 1978; Lorenzo Schiaffino, S., Origen de las ciudades chilenas. Las fundaciones del siglo XVIII, Andrés Bello, Santiago, 1983, y del mismo Lorenzo Schiaffino, S. y Urbina Burgos, R., La política de poblaciones en Chile durante el siglo XVIII, El Observador, Quillota, 1978.

${ }^{20}$ Una descripción de la situación de la época se puede encontrar en el trabajo de DE Ramón, A., Santiago de Chile (1541-1991). Historia de una sociedad urbana, Editorial Sudamericana Chilena, Santiago, 2000, pp. 185-187.

${ }^{21}$ Urbina, M., Los conventillos de Valparaíso, 1880-1920. Fisonomía y percepción de una vivienda popular urbana, $2^{\mathrm{a}}$ edición, Ediciones Universitarias de Valparaíso de la Universidad Católica de Valparaíso, Valparaíso, 2011, p. 85. 
prohíbe su construcción en un perímetro determinado de la ciudad y se señalan plazos para proceder a la demolición de las existentes; y continúa con la Ordenanza Municipal de 15 de abril de 1865, que define la exigencia obligatoria de cierros de propiedades y les asigna una altura mínima, justificada por razones de seguridad y de conformación del orden citadino ${ }^{22}$.

En este contexto, a comienzos de 1870 se plantea la necesidad de realizar una remodelación de la ciudad de Santiago, con el objeto de ordenar el casco urbano y hacer un nuevo trazado de la misma. En esta tarea, la labor de Benjamín Vicuña Mackenna resultó fundamental al desarrollar un "Plan de Transformación”, dentro de este se dicta la primera ley que se ocupa directamente de los problemas urbanos de la ciudad de Santiago: la "Lei sobre apertura i prolongación de calles i paseos públicos en la ciudad de Santiago", de 25 de junio de $1874^{23}$.

Sin embargo, esta ley se ocupó solo de un aspecto parcial relacionado con el ensanche de calles de la ciudad de Santiago, conteniendo diversas normas urbanísticas relativas a la edificación del suelo (alturas, ochavamiento, línea de edificación) ${ }^{24}$ y sendas declaratorias de utilidad pública de determinados sectores para su expropiación (artículos $2^{\circ}$ y $4^{\circ}$ ) y la fijación de una nueva línea de edificación (artículo $3^{\circ}$ ). En definitiva, con esta ley solo se pretendía lograr cierto orden urbanístico regulando la construcción de edificios y resolviendo la necesidad de mayores espacios públicos.

\section{Lei sobre transformación de la ciudad de Curicó, de 23 de junio de 1875}

Fuera de la ciudad de Santiago también se presentaba una situación similar con los sectores populares que se incorporaban a la ciudad. Así ocurrió con la ciudad de Curicó en donde lentamente fueron surgiendo barrios marginales en el antiguo damero colonial, además de una constante penetración de estas clases en sitios eriazos y no cercados dentro de la ciudad mediante rancheríos. Esta situación, según algunos autores, molestaba mucho a los grupos dominantes y se impuso la idea de marginarlos o segregarlos. A lo anterior se agregan las pésimas condiciones sanitarias de la ciudad y un limitado acceso al agua potable ${ }^{25}$.

Este escenario da lugar a la Ordenanza de Policía de 1873 que fijó los límites de la ciudad y estableció que todos los dueños de sitios eriazos ubicados en el interior debían ser cerrados, prohibiéndose la construcción y reconstrucción de habitaciones de material

${ }^{22}$ Gurovich W., A., "Conflictos y negociaciones: La Planificación Urbana en el desarrollo del Gran Santiago, Chile”, en Revista de Urbanismo, N², 2000, p. 6.

${ }^{23}$ De Ramón, A., "Estudio de una periferia urbana: Santiago de Chile 1850-1900”, en Historia, No 20, 1985, pp. 204-208; De Ramón, A. Santiago de Chile (1541-1991). Historia de una sociedad urbana. Santiago: Editorial Sudamericana Chilena, 2000, p. 146, pp. 145-146, y Romero, L., "Urbanización y sectores populares: Santiago de Chile, 1830-1875”, en EURE, 31, 1984, pp. 55-66.

24 Artículos $3^{\circ}, 6^{\circ}$ y $7^{\circ}$.

${ }^{25}$ Valenzuela, J., Estructuración del espacio popular en una ciudad intermedia: Curicó, 1870-1990, en Historia, $\mathrm{N}^{\circ} 25,1990$, pp. 255-259. 
ligero propio de los sectores populares. Además, se prohibió el tránsito de ganado por las calles interiores y la existencia de corrales con cerdos. Así, se restringió a los nuevos pobladores el acceso a lo que algunos llamaban "ciudad propia" o la "ciudad decente".

En este contexto se dicta la "Lei sobre transformación de la ciudad de Curicó”, de 23 de junio de 1875, con un contenido casi idéntico a la dictada para la ciudad de Santiago el año anterior. Así se consolida una forma de enfrentar el problema urbano a partir de la regulación legal de la anchura de las calles, la altura de edificios y la declaración de utilidad pública de determinados sectores.

\section{Lei sobre Transformación de la ciudad de Valparaíso de 11 de diciembre de 1876}

En la segunda mitad del siglo XIX se produjo el extraordinario crecimiento del puerto de Valparaíso, con un importante desarrollo comercial y demográfico. Sin embargo, Valparaíso no contaba con espacio para crecer en la parte plana, y la vida en altura conllevaba otros problemas, ya que los barrios estaban emplazados de forma vertical, lo que era opuesto a un esquema de sociabilidad horizontal como los de Santiago y Curicó, con serios problemas por falta de agua en los cerros y con dificultades para su bombeo. Por tal razón, la ciudad debía concentrarse y evitar su expansión ${ }^{26}$. Además, a lo anterior es factible agregar que no existían calles que comunicaran los cerros entre sí, hasta la construcción del Camino de Cintura a fines del siglo XIX. En este contexto se dicta la "Lei sobre Transformación de la ciudad de Valparaíso", de 11 de diciembre de 1876, que siguió en parte el modelo de sus predecesoras, pero adaptándose a las características de la ciudad.

Esta ley contemplaba algunos avances, aunque en lo sustancial se mantiene dentro de la regulación de policía. Así, parte estableciendo el ancho de calles y avenidas (artículos $1^{\circ}, 2^{\circ}$ y $3^{\circ}$ ); se contemplan expresamente limitaciones a los propietarios de casas esquinas (artículo $4^{\circ}$ ), también establece alturas máximas para los edificios (artículo $9^{\circ}$ ) y normas técnicas, especialmente al exigir determinados materiales para la construcción de ciertas edificaciones. Además, se establecen sendas prohibiciones para la construcción de ranchos, galpones y techos abiertos utilizando madera u otro material fácilmente combustible (artículo 10). Sin embargo, el aspecto más interesante de esta ley es la regulación para la creación de nuevos barrios e instalaciones de cierta envergadura (edificios públicos, fábricas, conventillos). Para tal efecto, se estableció un procedimiento bastante simple, que consistía en la aprobación municipal de los planos y especificaciones, especialmente con una finalidad sanitaria e higiénica. Este constituye un importante antecedente de las autorizaciones previas que darán origen al permiso de urbanización y de edificación ${ }^{27}$.

${ }^{26}$ Urbina, M., Los conventillos de Valparaíso, 1880-1920. Fisonomía y percepción de una vivienda popular urbana, $2^{\mathrm{a}}$ edición, Ediciones Universitarias de Valparaíso de la Universidad Católica de Valparaíso, Valparaíso, 2011 , p. 60.

27 Artículo 11. 
4. Lei $N^{0} 1.887$, de 6 de diciembre de 1906, sobre Trabajos que ordenan ejecutar para reparar daños causados a la ciudad de Valparaíso por el terremoto de agosto de 1906

El 18 de agosto de 1906 se produjo uno de los terremotos más grandes que ha sufrido Valparaíso, con una magnitud sobre los 8 grados. Ante dicha catástrofe, se dicta con fecha 6 de diciembre de 1906 la Ley $\mathrm{N}^{\circ} 1.887$ sobre Trabajos que se ordenan ejecutar para reparar los daños causados a la ciudad de Valparaíso por el terremoto de agosto de 1906. Si bien esta ley tiene un objeto bien preciso, cual es "precaver a esta ciudad de inundaciones i mejorar sus condiciones hijiénicas” (Artículo $1^{\circ}$ ), se introduce por primera vez la obligación de contar con un plano aprobado por la autoridad, al establecer que dichas obras se ejecutarían con arreglo a "los planos i a los límites que apruebe el Presidente de la República, oyendo a la Municipalidad respecto de las obras de carácter municipal”. Esta constituye la primera norma legal que introduce lo que más adelante será la técnica de la planificación urbana.

\section{Lei $N^{\circ}$ 2.004, de 10 de setiembre de 1907, que Declara de utilidad pública los terrenos necesarios para la apertura, ensanche i rectificación de las calles de Limache}

En 1907 se dicta una ley para la ciudad de Limache, con el único objeto de declarar de utilidad pública determinados terrenos para el ensanche y rectificación de las calles de dicha ciudad. En este caso el trazado de dichas calles debía realizarse en los planos que debía aprobar el Presidente de la República. Además, se impone a los propietarios la obligación de contribuir al pago de los costos de pavimentación de las calles y construcción de aceras frente a su propiedad, y considera la cesión gratuita de terrenos.

6. Lei $N^{\circ} 2.203$ de 7 de septiembre de 1909, que fija las disposiciones a que deberá sujetarse la construcción de edificios, apertura, ensanche, unión, prolongación o rectificación de calles de la ciudad de Santiago

A fines del siglo XIX Santiago era la principal ciudad del país. En 1895 la población sumaba 256.403 habitantes, que representaba el 9,5\% de la población total de Chile. Sin embargo, los problemas del crecimiento de la ciudad iban en aumento y era necesario enfrentarlos mediante un plan de transformación que comprendería los trazados viales y los espacios verdes. Esta labor se inicia en 1894 y concluye en 1909 con la promulgación de la Ley $\mathrm{N}^{\mathrm{0}} 2.203$, de 7 de septiembre de 1909, que fija las disposiciones a que deberá sujetarse la construcción de edificios, apertura, ensanche, unión, prolongación o rectificación de calles de la ciudad de Santiago ${ }^{28}$.

${ }^{28}$ En 1894 se elabora un "Plan de Transformación de la ciudad de Santiago" por parte del Director de Obras Municipales de Santiago, Ingeniero Manuel H. Concha, el que fue objeto de mucha discusión como consecuencia de los alcances que tenían las expropiaciones propuestas. En 1908 se crea una Junta de Transformación de Santiago, cuyo plan es aprobado en definitiva mediante la Ley $\mathrm{N}^{\circ} 2.203$. Si bien este cuerpo legal puso fin a la discusión del proyecto Concha, sacando los acápites conflictivos, se ha sostenido que 
Esta ley consolida la existencia de un plano que debe aprobar la Municipalidad para el trazado de las calles, plazas y avenidas, e insiste en fijar la anchura mínima de las calles de la ciudad: 15 metros entre las líneas de construcción de ambos lados ${ }^{29}$. Sin embargo, lo más relevante es la exigencia de un permiso para edificar, como mecanismo de control preventivo para el cumplimiento de las normas de dicha ley y los trazados fijados en el plano: "En la ciudad de Santiago nadie podrá edificar sin que previamente la autoridad municipal haya fijado la línea de la vía pública correspondiente al exterior del edificio" 30 .

También se establece una declaración general de utilidad pública para llevar a efecto la transformación de Santiago ${ }^{31}$ y se fijan sanciones para los funcionarios y particulares que infrinjan las disposiciones de este cuerpo legal, otorgando una acción popular para denuncias a dichas infracciones ${ }^{32}$.

En definitiva, la consolidación del plano como técnica de ordenación y la existencia de un control preventivo mediante un permiso previo para edificar, constituyen los aspectos más relevantes que se pueden destacar de esta ley. Sin embargo, si bien su artículo $2^{\circ}$ exigía la aprobación de un plano maestro complementario aprobado por la Municipalidad que definiera las rectificaciones y jerarquizara las vías y los otros espacios, dicho plano no se llega a formular. Además, se desata un creciente gasto municipal que traba su ejecución, debido a la insolvencia en las operaciones puntuales, desorientando sus objetivos, aumentando la incertidumbre y terminando por producir un paisaje de alineamientos discontinuos generalizados. Por tal razón, a la Ley No 2.203 se le conocerá también como la "Ley Serrucho"33.

\section{Lei $N^{\circ} 2.196$ de 17 de setiembre de 1909, sobre la Transformación de la ciudad de Talca}

Como otras ciudades de Chile, Talca incrementó su población de forma sostenida desde la segunda mitad del siglo XIX, teniendo 14.144 en 1854 y llegando a los 38.040 en 1907. Curiosamente en este caso fue el desarrollo de la agricultura el principal estímulo para la concentración de población urbana, a diferencia de lo que sucedía en Santiago y Valparaíso ${ }^{34}$. A 1875 el 73,2\% de la población se localizaba en el ámbito rural, disminuyendo a 53,3\% en 1907 y llegando a una nivelación porcentual hacia 1910.

terminó desvirtuando absolutamente la propuesta original. Véase Aguirre, B. y Castillo, S., Para una comprensión del espacio público urbano en Santiago de Chile: la segunda mitad del siglo XIX y la época del Centenario, Centro de Estudios Arquitectónicos, Urbanísticos y del Paisaje, Universidad Central, Santiago, 2002, pp. 45-46.

29 Artículos $2^{\circ}$ y $3^{\circ}$.

${ }^{30}$ Artículo $6^{\circ}$.

31 Artículo 12.

32 Artículos 22 y 23.

33 Gurovich W., A., "Conflictos y negociaciones: La Planificación Urbana en el desarrollo del Gran Santiago, Chile”, en Revista de Urbanismo, No 2, 2000, p. X.

${ }^{34}$ Cortez, A., Sociedad y cultura en Talca, 1910: la provincia y el Centenario Nacional, Consejo Nacional de la Cultura y las Artes, Talca, 2013, pp. 50-51, y De Ramón, A., "Un progreso interrumpido: El caso de Talca durante la segunda mitad del siglo XIX”, en EURE, No 62, 1995, pp. 40-42. 
Aquello da lugar a una mayor extensión del damero original de la ciudad hacia el norte y el poniente. En un primer momento, los sectores populares pueden hacerse de una vivienda en esta nueva parte de la ciudad loteada por la Municipalidad, pero luego la mayor densificación y el aumento del valor del suelo urbano obligaron a los obreros y jornales a alquilar en conventillos y cités construidos por las clases acomodadas. Por estas razones, especialmente de carácter sanitario, la Municipalidad dicta en 1898 un "Reglamento sobre conventillos y policía de cuartos redondos", aunque su cumplimiento solo fue parcial. Posteriormente, tiene lugar la celebración del primer Centenario del país, lo que motivó diversas acciones de mejora urbana, incluyendo la forma de enfrentar la situación de las clases menesterosas ${ }^{35}$. En este contexto es que se dicta la Lei $\mathrm{N}^{\circ}$ 2.196, de 17 de setiembre de 1909, sobre la "Transformación de la ciudad de Talca". Ahora bien, este cuerpo legal refuerza la exigencia del permiso municipal para edificar y reconstruir edificios en los costados de las calles, plazas y otros bienes nacionales de uso público ${ }^{36}$. Además, por primera vez se fijan a nivel legal los límites urbanos de la ciudad, los que son señalados con todo detalle, y se indica con precisión las calles que deberán ser abiertas e incluso las manzanas que deberán ser expropiadas para construir una nueva plaza $^{37}$. En la misma línea, la ley viene acompañada de un plano que fija el límite urbano y establece el trazado de las nuevas calles ${ }^{38}$, y señala además la anchura que tendrán cada una de ellas ${ }^{39}$. También se insiste en la obligación de ochavar que tienen los propietarios de casas esquinas, debiendo ceder a la vía pública dichos terrenos ${ }^{40} \mathrm{y}$ se declara de utilidad pública todos los terrenos necesarios para ejecutar las obras ${ }^{41}$.

Como bien se puede apreciar, se trata de una ley muy concreta, que indica con el mayor detalle las obras que se deben realizar y que cumple una verdadera función de planificación urbana, al contener no solo normas sino también el plano respecto del trazado de las vías y las líneas de edificación.

\section{Lei $N^{\circ} 2.297$ de 9 de marzo de 1910, sobre la Transformación i reconstrucción de la ciudad de Valdivia}

La situación de Valdivia a 1910 está marcada por una de las tantas catástrofes que le ha tocado padecer. El 13 de diciembre de 1909 se desató un incendio que destruyó cerca de 20 manzanas que comprendían las últimas residencias virreinales, hoteles, bancos, colegios, la Iglesia Matriz, la Intendencia, el Obispado, además de un sinnúmero de viviendas. Con esto desapareció todo el diseño urbano de Valdivia desde 1797. La visita

${ }^{35}$ Cortez, A., Sociedad y cultura en Talca, 1910: la provincia y el Centenario Nacional, Consejo Nacional de la Cultura y las Artes, Talca, 2013, pp. 55 y 168.

36 Artículos $1^{\circ}$ y $5^{\circ}$.

37 Artículo $7^{\circ}$.

38 Artículo $8^{\circ}$.

39 Artículo $9^{\circ}$.

40 Artículo 10.

41 Artículo 11. 
de las máximas autoridades del país no se hizo esperar y a dos días de la catástrofe llega al lugar el presidente Pedro Montt junto con su ministro del Interior Ismael Tocornal ${ }^{42}$. Debido a las circunstancias, se diseña un plan de reconstrucción que comprende, entre otras medidas, la dictación de la Ley $\mathrm{N}^{0}$ 2.297, de 9 de marzo de 1910, sobre la “Transformación i reconstrucción de la ciudad de Valdivia”. Salvo por las circunstancias descritas, esta ley sigue en la línea de sus predecesoras. En ella se dispone expresamente que el trazado de las calles, plazas y avenidas deberá sujetarse a las líneas que se fije en un plano, el que deberá ser aprobado por el Presidente de la República con acuerdo de la Municipalidad de Valdivia ${ }^{43}$. Además, de forma estricta se prohíbe la apertura de nuevos barrios de población dentro del radio de la comuna, sin que previamente la Municipalidad haya aprobado los planos que le presenten los interesados, y se coloca de cargo de ellos la entrega de calles pavimentadas y con sus aceras construidas ${ }^{44}$. También se establece la obligación de obtener un permiso de la Municipalidad para edificar al costado de calles, plazas u otros bienes nacionales de uso público ${ }^{45}$, manteniéndose las normas sobre voladizos y de ochavamiento de las esquinas ${ }^{46}$. Por último, se insiste en declarar de utilidad pública todos los terrenos necesarios para llevar a efecto la transformación de Valdivia ${ }^{47}$, junto con establecer sanciones para los funcionarios y particulares que infringieren sus disposiciones ${ }^{48}$.

En definitiva, esta ley no tuvo por objeto afrontar una reforma, sino asumir la reconstrucción de una ciudad devastada, para ello se utilizaron las técnicas ya contenidas en las anteriores leyes de las ciudades de Santiago, Valparaíso, Talca y Curicó, por lo que representa una buena síntesis de sus predecesoras.

\section{Lei número 2.658 de 13 de junio de 1912, sobre la Construcción de edificios $i$ la apertura, ensanche, unión, prolongación o rectificación de calles, avenidas i plazas en la ciudad de Concepción}

A fines del siglo XIX y comienzos del siglo XX, la ciudad de Concepción experimentó un gran crecimiento demográfico producto de la grave crisis que sufrió el sistema exportador en las zonas rurales, unido al desarrollo industrial que transformó a esta ciudad en un polo de atracción para los campesinos y los habitantes de pequeñas ciudades del entorno. En esas condiciones, la ciudad no pudo albergar a las personas que llegaban en masa, surgiendo el convenillo como el lugar de asiento de campesinos, obreros y artesanos. Nuevamente la vieja trama urbana colonial no daba respuesta al proceso social que se estaba viviendo y era necesario realizar una transformación. Así, en 1912

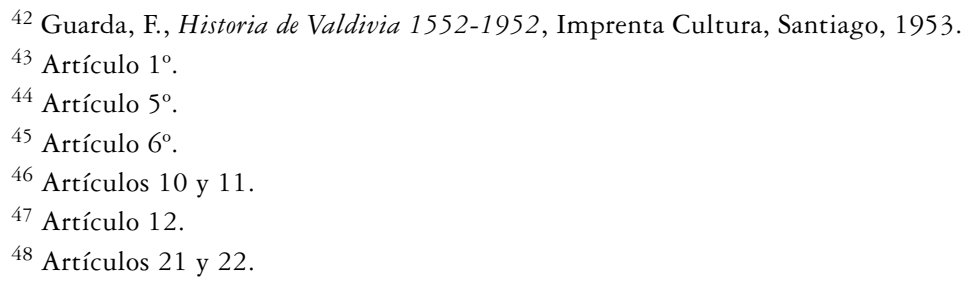


se dicta Ley $\mathrm{N}^{\circ}$ 2.658, de 13 de junio, sobre "La construcción de edificios i la apertura, ensanche, unión y prolongación o rectificación de calles, avenidas y plazas en la ciudad de Concepción”. Este cuerpo legal resume también la tradición anterior utilizando una técnica muy básica de planificación mediante planos ${ }^{49}$, establece la licencia o permiso para abrir nuevos barrios o edificar al costado de calles, plazas u otros bienes nacionales de uso público, y fija directamente el límite urbano ${ }^{50}$. Además, se impone como una carga del propietario las obras de urbanización, señalando expresamente que estas obras comprenden las calles pavimentadas, sus servicios de alcantarillado, iluminación, agua potable y sus aceras ${ }^{51}$. Así, se consolidan las cesiones gratuitas de aquellos suelos afectados al uso público una vez que se autoricen las obras de urbanización, como aparecía en la Ley de Valdivia, sin perjuicio de la posibilidad de expropiarlas ${ }^{52}$.

En definitiva, esta ley, junto con la de la ciudad de Valdivia, recoge las técnicas más rudimentarias de intervención en la ciudad, en un período inicial de nuestro Derecho urbanístico, marcado por el concepto decimonónico de propiedad como limitaciones a la misma dentro del concepto clásico de policía. De este modo, el propietario tiene el protagonismo en la acción urbanística y a la Administración le corresponde la tarea de establecer algunas limitaciones, diseñar calles y alineaciones y, en su caso, construirlas.

\section{La síntesis del Derecho urbanístico inicial: la Lei Sobre Organización i Atribuciones de las Municipalidades de 28 de enero de 1915}

La regulación contenida en las primeras normas urbanísticas en nuestro país fue recogida con carácter general en una reforma a la Ley de Municipalidades de 1915. La idea matriz de esta normativa sigue siendo la misma: la iniciativa en la producción de nuevo espacio urbano recae en los propietarios, dentro del marco general fijado por las municipalidades. Esta ley dispone que la formación de los nuevos barrios está sujeta a aprobación por parte de la Municipalidad; regula con mayor detalle las cesiones gratuitas, que pasan a ser una carga propia del proceso de urbanización y que la jurisprudencia de la época consideró que no constituían una lesión a la inviolabilidad del dominio garantizada constitucionalmente ${ }^{53}$; se precisa aún más el detalle del conjunto de obras a cargo del propietario que comprende la urbanización (pavimentación de calles, aceras, avenidas, plazas, servicio de alumbrado público, agua potable y desagües); así como una

${ }^{49}$ Respecto de la planificación el artículo $2^{\circ}$ disponía que "el trazado de las calles, plazas y avenidas se sujetarán a las líneas fijadas en el plano acordado por la Municipalidad que apruebe el Presidente de la República”.

${ }^{50}$ Artículos $3^{\circ}, 4^{\circ}$ y 20.

${ }^{51} \mathrm{El}$ artículo $3^{\circ}$ inc. $2^{\circ}$ lo establece en los siguientes términos: "Para que la Municipalidad pueda aceptar la apertura de un nuevo barrio o población, es necesario que el interesado se obligue a entregar las calles pavimentadas, con sus servicios de alcantarillado, iluminación i agua potable, i sus aceras en la forma i condiciones que dicha Municipalidad acuerde con arreglo a las leyes".

52 Artículo 10.

53 Véase Gaceta de los Tribunal, 1919, $2^{\circ}$ Semestre, Nº6, p. 366. 
referencia a las condiciones de seguridad, higiene y estética de las construcciones ${ }^{54}$. De esta forma, la Ley de Municipalidades constituye una ley marco que establece las atribuciones generales de las municipalidades en materia de urbanización y creación de nuevos barrios, junto con algunas normas sustantivas acerca de los deberes que tienen que asumir los propietarios, haciendo una amplia remisión a las ordenanzas locales y a la discrecionalidad de los municipios.

\section{El Derecho urbanístico integrado}

Hablamos de Derecho urbanístico integrado en los casos en que la legislación enfrenta la cuestión urbana a partir de un sistema que comprende un conjunto de técnicas de intervención en el uso y gestión del suelo, todas estas están necesariamente trabadas y condicionadas recíprocamente, partiendo desde la planificación previa, la zonificación del suelo o asignación de usos, la conformación de un estatuto para los propietarios en relación con cada clase de suelo, y un conjunto de mecanismos de control previo (permisos o autorizaciones), así como represivos, que tienen por objeto la implementación de un determinado modelo de ordenación territorial.

En nuestro país, este proceso tiene lugar mediante diversos cuerpos legales:

${ }^{54}$ Todo lo anterior se resume en los nuevos incisos incorporados al numeral 1 del artículo 25 de la Ley de Municipalidades por la Ley No 2.960, de 23 de 1915, y que establecen lo siguiente:

"No se podrá proceder a la formación de nuevos barrios dentro de los límites urbanos de las ciudades, por medio de la división de propiedades i de su venta en sitios, sin que los interesados hayan sometido previamente a la aprobación de la Municipalidad el plano respectivo, en el cual se determinará la ubicación i dimensiones de las vías i plazas que se propongan formar.

Una vez aprobado el plano, el dueño del terreno deberá otorgar una escritura pública con el Fisco, en que ceda gratuitamente al dominio nacional de uso público la parte destinada a dichas vías i plazas. Esta escritura se inscribirá en el Rejistro Conservador de Bienes Raíces, para cancelar el dominio privado de esos bienes.

El dueño del terreno estará obligado a pavimentar a su costa, i en la forma que determine la Municipalidad, las nuevas calles i sus aceras, las avenidas y plazas; a instalar el servicio de alumbrado público que la misma ordene; a dotar al barrio de las instalaciones requeridas para los servicios de agua potable i desagües hijiénicos. Todas estas obras pasarán a ser de propiedad municipal desde que se entreguen al servicio. La Municipalidad podrá exijir el establecimiento del alcantarillado en las ciudades en que este servicio no exista. En este caso, el dueño del terreno, si el terreno fuere regado, deberá ceder, a beneficio de la Municipalidad, la dotación de agua corriente necesaria para abastecerlo.

Las construcciones que se emprendan en las nuevas poblaciones o barrios deberán consultar, a lo menos, las condiciones de seguridad, hijiene i apariencia esterior adoptadas en las construcciones oficiales de casas para obreros del Consejo Superior de Habitaciones Obreras.

Los sitios deberán cerrarse, a lo menos, con malla de alambre.

Las disposiciones que contiene el presente número se entenderán sin perjuicio de las medidas de protección que establece la ley número 1,838, de 20 de Febrero de 1906”. 


\section{La Ley $N^{\circ}$ 4.563, de 14 de febrero de 1929, sobre construcciones antisísmicas}

En 1929 se dará impulso a una normativa más íntegra y sistemática en materia urbanística. Esta regulación estará determinada por un hecho concreto, como fue el terremoto que estremeció las ciudades de Talca, Constitución y Curicó de 1928. Esta catástrofe dejó al descubierto el mal estado de las construcciones, así como la ineficacia de la normativa urbanística vigente a la época. Además, las competencias entregadas a las municipalidades en la materia no se materializaban de la mejor forma, al no contar con la capacidad presupuestaria y técnica adecuada. Por último, la iniciativa de la acción urbana descansaba en los propietarios, el que se llevaba a cabo sin un control adecuado, sin perjuicio de que en muchos casos se realizaba al margen de la escasa legislación vigente. Bien decía José Tomás Urmeneta que "completa libertad hay en Chile para que cada cual edifique sus habitaciones como mejor le cuadre" 55 .

En este año se aprueba la Ley $\mathrm{N}^{\circ} 4.563$, de 14 de febrero, sobre construcciones antisísmicas, promovida por el Ministro de Fomento Luis Schmidt Quezada, siendo su principal redactor el arquitecto Luis Muñoz Maluschka ${ }^{56}$. Este cuerpo legal facultó al Presidente de la República para dictar ordenanzas generales en esta materia, las que tuvieron una particular forma de elaboración y de entrada en vigencia ${ }^{57}$.

Ahora bien, esta ley insistirá en el permiso municipal previo para construir en las localidades de más de 5.000 habitantes ${ }^{58}$. Además se crea un cargo administrativo de carácter técnico con el nombre de "Director de obras municipales", que tiene como tarea la aplicación de las disposiciones de dicha ley ${ }^{59}$; se establece el deber de las municipalidades

${ }^{55}$ Urmeneta, J., Disposiciones legales y municipales para la construcción de edificios, Imprenta Diner, Santiago, 1915.

56 Aguirre, B. y Castillo, S., "El espacio público moderno. Sueños y realidades de Karl Brunner en Santiago de Chile, 1929-1934”, en Diseño Urbano y Paisaje, N 3, vol. I, 2005, p. 10; Schmidt, L., Legislación y reglamentación de construcciones y urbanización, Santiago, 1935, y Arrieta, B., Estudio Sobre la Ley de Construcciones y Urbanización, Memoria de Prueba para optar el grado de Licencias en Ciencias Jurídicas y Sociales de la Universidad de Chile, Editorial Jurídica de Chile, Santiago, 1954.

${ }^{57}$ El artículo $1^{\circ}$ de la Ley $\mathrm{N}^{\circ} 4.563$ establecía esta delegación legislativa respecto de una amplia variedad de materias, que comprende "[...] normas a que deberá someterse la construcción de edificios y otras obras, en las distintas zonas del país, determinando su altura máxima y mínima, la naturaleza de sus materiales, las condiciones que deben reunir para impedir su caída y la propagación de los incendios y para evitar en lo posible los riesgos provenientes de terremotos u otros fenómenos, especialmente en lo relativo a teatros, iglesias, hoteles y demás establecimientos destinados a reunir gran número de personas [...] condiciones mínimas de higiene, salubridad y aspecto exterior que deben reunir los edificios, según su naturaleza y ubicación, pudiendo facultar a la autoridad comunal para que decrete la destrucción o reparación de las que amenacen ruinas, tanto interior como exteriormente".

${ }^{58}$ Se establece que nadie puede "construir, reconstruir ni efectuar reparaciones o transformaciones de importancia, sin permiso de la autoridad comunal [...] en las grandes construcciones o en las de naturaleza especial, la autoridad local podrá exigir que, junto con los planos y especificaciones, se le presenten los cálculos de estabilidad".

59 Artículo $4^{\circ}$. Esta norma dispone que el cargo era de "Director de Obras municipales, Ingeniero o Arquitecto, encargado de todo lo relacionado con el estudio y aplicación de las disposiciones pertinentes de la presente ley". 
en las ciudades de más de 20.000 habitantes de elaborar un anteproyecto de transformación de la ciudad, que debía ser ultimado y aprobado por el Presidente de la República; y, por último, considerando la mayor intervención que tendrán las municipalidades y la necesidad de recursos financieros para emprender las transformaciones urbanas, se les faculta para emitir bonos con el fin de pagar con dichos fondos las indemnizaciones que deriven de las expropiaciones de los terrenos declarados de utilidad pública para ejecutar los planos ${ }^{60}$. No obstante, con estas normas no se pretendía crear un sistema de financiación de la acción urbanística que internalizara en alguna medida las plusvalías que esta genera. En efecto, esta ley tenía por objeto establecer un mayor control de la calidad de la construcción por parte de las municipalidades. Además, sus alcances eran más bien limitados, ya que son una respuesta a una contingencia más que en una real política urbana, como venía ocurriendo con toda la legislación dictada a la fecha. Sin embargo, este cuerpo normativo es considerado por algunos autores como la primera Ley de Construcciones y Urbanización ${ }^{61}$, y claramente constituye el antecedente de lo que posteriormente dará lugar a un Derecho urbanístico integrado.

\section{La "Ley General sobre Construcciones y Urbanización" y su "Ordenanza", aprobada mediante el DFL N³45, de 30 de mayo de 1931}

En virtud de la delegación conferida por la Ley $\mathrm{N}^{\circ} 4.563$, el gobierno de la época tomó la determinación de nombrar una comisión de expertos integrada por arquitectos, ingenieros y abogados, para que elaborara un Proyecto de Ordenanza General de Construcciones y Urbanización ${ }^{62}$. Esta comisión tomó como antecedentes los principales cuerpos normativos vigentes a la época en el derecho comparado, así como una Ordenanza de Construcciones que había trabajado durante largo tiempo la Dirección de Obras Municipales de la Municipalidad de Santiago con sus asesores jurídicos. El texto también habría sido objeto de observaciones por parte de dos destacados urbanistas extranjeros que visitaron nuestro país: Karl Brunner y Jacques Lambert, quienes asesoraron a diversas entidades públicas y gubernamentales en estas materias.

El trabajo de la comisión se plasmó en unas Ordenanzas que fueron más allá de la delegación prevista en la Ley $\mathrm{N}^{\mathrm{0}}$ 4.563. Por esta razón, los comisionados propusieron que fuera nuevamente sometida a la aprobación del Congreso. Sin embargo, el gobierno adoptó la decisión de aprobarlas mediante el Decreto $\mathrm{N}^{\circ} 304$, de 14 de enero de 1930 , dejando expresa constancia que tenían un carácter provisional (dos años) y que solo eran aplicables en las materias comprendidas en la ley delegante. Nuevamente en esta etapa

\footnotetext{
${ }^{60}$ Artículos $8^{\circ}$ y $9^{\circ}$.

${ }^{61}$ Fernández, J. y Holmes, F., Derecho Urbanístico Chileno, Editorial Jurídica de Chile, Santiago, 2008, p. 37.

62 Arrieta, B., Estudio Sobre la Ley de Construcciones y Urbanización, Memoria de Prueba para optar el grado de Licenciado en Ciencias Jurídicas y Sociales de la Universidad de Chile, Editorial Jurídica de Chile, Santiago, 1954.
} 
tuvo activa participación don Luis Schmidt Quezada, quien integraba esta comisión y redactó el decreto con estas prevenciones ${ }^{63}$.

Sin embargo, en 1931 se adoptó la decisión de dictar una nueva Ley General de Construcciones y Urbanización, junto con aprobar las Ordenanzas que regían provisionalmente en la parte autorizada por la ley, aunque con algunas modificaciones. Para dicho efecto ya no se utilizó la delegación contenida en la Ley $\mathrm{N}^{\circ} 4.563$ de 1929, sino que se recurrió a otra norma habilitante y más amplia, como fue la Ley $\mathrm{N}^{\circ} 4.945$, de 6 de febrero de 1931. De esta forma, se dictó el DFL N³ 345, de 30 de mayo de 1931, que aprueba la "Ley y Ordenanza General sobre Construcciones y Urbanización", aunque sin dar cuenta de su contenido y haciendo una mera referencia a estos cuerpos normativos como documentos adjuntos, en los siguientes términos:

\footnotetext{
"Vistas las facultades que me confiere la ley N.o 4,945, de 6 de Febrero del presente año,

Decreto:

Apruébase la adjunta ley y Ordenanza General sobre Construcciones y Urbanización. Dos ejemplares de una edición correcta y esmerada autorizada por el Presidente de la República, y signados con el sello del Ministerio del Interior, se depositarán en la secretaría de ambas Cámaras; dos en el archivo de este Ministerio y otros dos en la Biblioteca Nacional".
}

A pesar de lo anterior, el gobierno no puso en aplicación estas normas, por lo que mantuvieron su vigencia la Ley $\mathrm{N}^{0} 4.563$ y la Ordenanza aprobada de forma provisional mediante el Decreto No 304, de 1930. Para tales efectos se prorrogaron por períodos de un año, hasta cumplir un total de cinco, cuando se adoptó la decisión de que ambos cuerpos normativos entraran en vigencia mediante su publicación en el diario oficial, lo que ocurrió el 6 de febrero de $1936^{64}$.

Ahora bien, estas normas contendrán por primera vez un conjunto sistemático de disposiciones concernientes a construcción y urbanización, regulando diversas técnicas de intervención por parte de la Administración. A su vez, la ley es más que una síntesis del conjunto de normas que se habían dictado desde mediados del siglo XIX, ya que en 94 artículos más 2 disposiciones transitorias establece reglas para la construcción de edificios (permisos, inspecciones, de los profesionales que intervienen, etc.); de la urbanización de las ciudades (incluidos los planos de urbanización, la línea

63 Arrieta, B., Estudio Sobre la Ley de Construcciones y Urbanización, Memoria de Prueba para optar el grado de Licenciado en Ciencias Jurídicas y Sociales de la Universidad de Chile, Editorial Jurídica de Chile, Santiago, 1954, p.157] y Schmidt, L., Legislación y reglamentación de construcciones y urbanización, Santiago, 1935.

${ }^{64}$ Fernández, J. y Holmes, F., Derecho Urbanístico Chileno, Editorial Jurídica de Chile, Santiago, 2008, p. 37]; W., A., "Conflictos y negociaciones: La Planificación Urbana en el desarrollo del Gran Santiago, Chile”, en Revista de Urbanismo, No 2, 2000, p. 19; Arrieta, B., Estudio Sobre la Ley de Construcciones y Urbanización, Memoria de Prueba para optar el grado de Licenciado en Ciencias Jurídicas y Sociales de la Universidad de Chile, Editorial Jurídica de Chile, Santiago, 1954, pp. 157-158. 
de edificación, de altura y aspecto exterior de los edificios, de la formación de barrios y apertura de calles, entre otros); de las expropiaciones y de las sanciones. Sin embargo, tampoco significó un cambio radical en la concepción de la función pública del urbanismo, ya que se mantiene como centro de gravedad la actividad privada, sustentada en el derecho de los propietarios tanto en la actividad de urbanización como en la edificación. En este caso la actuación pública está limitada a la aprobación de planos de urbanización ${ }^{65}$, al otorgamiento de permisos o licencias ${ }^{66}$, al ejercicio de potestades de fiscalización, demolición y sanción ${ }^{67}$ y, de forma más excepcional, al ejercicio de la potestad expropiatoria para obtener el suelo necesario para los elementos dotacionales (calles, plazas, áreas verdes) $^{68}$, lo que era sin perjuicio de las cesiones gratuitas que deben hacer los propietarios ${ }^{69}$. Además, la planificación solo se extiende hasta lo que se conoce como área urbana ${ }^{70}$. No obstante se debe destacar una mejora en las técnicas de regulación, contemplando normas acerca de zonificación ${ }^{71}$, superficie de ocupación, altura $^{72}$ y estética ${ }^{73}$.

En definitiva, la Ley General sobre Construcciones y Urbanización de 1931 constituyó uno de los avances más importantes en la regulación de la actividad urbanística, distinguiendo con claridad el proceso de urbanización del uso y edificación del suelo. Si bien para algunos autores esta ley no hace sino establecer un detalle agobiante de limitaciones y de directas privaciones del dominio ${ }^{74}$, las técnicas de intervención están mejoradas. Además, el sistema diseñado por esta ley tenía un sesgo claramente liberal y centrado en el derecho de propiedad. De hecho, le confiere no solo la preferencia en la acción urbanística a los propietarios, sino también la facultad de decidir si se va a llevar adelante o no la transformación del suelo.

3. El Decreto con Fuerza de Ley $N^{o} 224$, del Ministerio de Hacienda, de 5 de agosto de 1953, que fija el Texto de la Ley General de Construcciones y Urbanización

Si bien esta la Ley General sobre Construcciones y Urbanización de 1931 fue objeto de varias modificaciones, la más importante se produce en 1953 con la dictación del Decreto con Fuerza de Ley No 224, del Ministerio de Hacienda, publicado el 5 de agosto

65 Todas las ciudades con más de 8.000 habitantes debían tener un plano oficial de urbanización (artículo 37).

${ }^{66}$ No se podía construir, reconstruir, ni efectuar reparaciones en un edificio, sin permiso de la Dirección de Obras Municipales (artículo $8^{\circ}$ ).

${ }^{67}$ Artículos 15, 16, 17, 20, 30 y 34.

68 Artículo 40.

69 Artículos 59, 62 y 64.

${ }^{70}$ Artículo 43. En el área rural se establece una prohibición general de abrir calles, formar poblaciones o levantar construcciones de cualquier clase, salvo aquellas que fueren necesarias para la explotación agrícola

71 Artículos 53 y 54.

72 Artículo 45.

73 Artículos 49, 51 y 52.

${ }^{74}$ Brahm, E., Propiedad sin Libertad. Chile 1925-1973, Universidad de los Andes, Santiago, 1999, p. 75. 
de 1953. Mediante la Ley $\mathrm{N}^{\circ} 11.551$, de 5 de febrero de 1953, se facultó al Presidente de la República para reorganizar las diferentes ramas de la Administración pública, indicándose de forma específica la facultad "para modificar, coordinar y refundir las disposiciones de la ley y ordenanza general de construcciones y urbanización y las que se refieren a materias similares, con informes del Colegio de Arquitectos, del Instituto de Ingenieros, de la Cámara Chilena de la Construcción y del Instituto Nacional de Urbanismo" (artículo 15 inc. $4^{\circ}$ ).

En la exposición de motivos del DFL $\mathrm{N}^{\circ} 224$, de 1953 , se indican claramente cuáles fueron las consideraciones que se tuvieron presentes al momento de la dictación de este nuevo cuerpo legal: reducir las exigencias para la construcción de habitaciones económicas, como un complemento del plan general del Estado de solución integral del problema de la vivienda; enfrentar el problema de las ciudades que están integradas por diferentes comunas y que no tienen un plano de conjunto; resolver en la formación de nuevas poblaciones, las negociaciones dolosas que afectaban a compradores de sitios que no cumplían con la ley y les impedía obtener su título de dominio, además de solucionar el problema creado a los adquirentes de sitios en poblaciones cuyos fundadores no han cumplido con las exigencias de urbanización; y perfeccionar el procedimiento para las expropiaciones que se deben realizar para el cumplimiento de los planos reguladores.

Este nuevo texto legal contiene innovaciones de interés, tanto en la forma de regular esta materia como respecto de la manera de ordenar los espacios y determinar los usos más allá del ámbito local. En primer término, y luego de establecer algunas disposiciones generales, este cuerpo legal altera el orden de su predecesora en la regulación de la cuestión urbana, partiendo por la planificación (Título II); siguiendo con la urbanización al tratar la apertura de calles y la formación de poblaciones y barrios nuevo (párrafo II del mismo Título II); continúa con las expropiaciones como principal instrumento de gestión (Título III); para hacerse cargo recién de las reglas relativas a la construcción de edificios (Título IV) y cerrar con las sanciones (Título V). Este nuevo orden en la regulación tiene un sentido bastante claro. Por una parte, se establece concretamente la forma en que se desencadena el proceso urbano, el que va desde la planificación, la urbanización y creación de nuevos barrios, hasta cerrar con la edificación del suelo. Por otra parte, en este caso se deja claramente establecido que todo el proceso de uso y edificación del suelo necesariamente debe ir precedida de una planificación previa de la mano de la autoridad pública, y que exige no solo determinar las clases de suelo, la definición de los espacios públicos y las normas de uso y edificación, sino que necesariamente deben ir acompañados de un proceso de transformación del suelo para contar con elementos básicos de habitabilidad mediante su urbanización. Solo a partir de este momento es posible contar con suelo edificable y, por tanto, es posible ejercer el ius aedificandi conforme con las normas del plan.

Además, también se debe destacar un cambio sustancial en la planificación urbana, al incorporar la figura de los planes reguladores a nivel intercomunal y comunal. El texto original de 1931 hablaba solo de planes de urbanización. Ahora se consolida la denominación de "Planos Reguladores", distinguiendo entre Plano Regulador Comunal e Intercomunal. A su vez, se define el Plano Regulador Intercomunal como aquel que 
de acuerdo con el Plano Regional ${ }^{75}$, organiza la vida colectiva en las comunas del país y en el que se ordenan armónicamente las viviendas, el trabajo, el esparcimiento, el transporte y la movilización ${ }^{76}$. El Plano Regulador Comunal es definido como aquel que de acuerdo con el Plano Regulador Intercomunal, ordena y da normas respecto de obligaciones, prohibiciones y disposiciones del uso del suelo y de la edificación en la comuna, con el objeto de dar a la población las máximas condiciones de higiene, de seguridad, de comodidad y de estética ${ }^{77}$.

No obstante lo anterior, el primer plan regulador que se dictó en Chile fue previo a esta regulación, en 1939, para la comuna de Santiago ${ }^{78}$. Por su parte, en 1960 se dicta el Plan Regulador Metropolitano de Santiago, comprendiendo a todas las comunas del "Gran Santiago", extendiendo por primera vez la planificación a una dimensión supralocal.

\section{El Decreto con Fuerza de Ley $N^{\circ}$ 458, de 13 de abril de 1976, Ley General de Urbanismo y Construcciones}

La situación urbana de las ciudades de nuestro país comienza a agravarse aún más, especialmente en Santiago, debido a que se acentúa la emigración de la población desde el campo a la capital, dando lugar a una población urbana bastante pobre, carente de una vivienda digna y, sobre todo, ubicada en espacios donde la urbanización era insuficiente (pavimentación, agua, luz, alcantarillado). Si bien este proceso social ya se venía gestando desde fines del siglo XIX, las necesidades habitacionales y urbanas se tornan particularmente urgentes en los inicios de la década de los cincuenta del siglo pasado ${ }^{79}$. Ahora bien, a partir de este momento el problema habitacional constituye el eje central de la política urbana, y el Estado lo aborda mediante el desarrollo de políticas y planes de vivienda que parten en los gobiernos de la década del cincuenta hasta la fecha. Sin embargo, la incapacidad de llevar adelante estas políticas a la par de las necesidades sociales, acentuaron la ocupación ilegal de terrenos por parte de la población y el surgimiento de los campamentos, que fue uno de los fenómenos de mayor impacto en la realidad urbana de Santiago entre 1970 y 1973 , y que ha sido calificado como el último intento de los pobladores para encontrar una solución a sus problemas habitacionales ${ }^{80}$.

75 A pesar de la referencia a un Plano Regional, este no aparece regulado en la ley. Posteriormente aparecerá en el DFL No 458 de 1976, con la denominación de Plan Regional de Desarrollo Urbano.

76 Artículo $8^{\circ}$.

77 Artículo $9^{\circ}$.

78 Este plan regulador comenzó a ser elaborado en 1934 por el urbanista austriaco Karl Brunner, quien preparó un "Anteproyecto regulador de la comuna de Santiago". Posteriormente asumió el trabajo el arquitecto Roberto Humeres, quien concluyó el plan en 1939, siendo aprobado el mismo año. Véase DE Ramón, A., Santiago de Chile (1541-1991). Historia de una sociedad urbana, Editorial Sudamericana Chilena, Santiago, 2000, p. 222.

${ }^{79}$ De Ramón, A., Santiago de Chile (1541-1991). Historia de una sociedad urbana, Editorial Sudamericana Chilena, Santiago, 2000, pp. 237-255.

80 Ídem. pp. 250-251. 
En esta línea, el gobierno militar adoptó la determinación de asumir la tarea de revisar en primer término la legislación urbana, sobre las base de dos presupuestos: a) Que la Ley General de Construcciones y Urbanización, su Ordenanza General, y las leyes, reglamentos y ordenanzas que rigen las instalaciones de agua potable, alcantarillado, gas y electricidad, adolecen, en general, de notoria obsolescencia en muchas de sus disposiciones, y b) Que era necesario propender a la mejor utilización de los recursos técnicos y materiales, y disminuir el costo de las construcciones, lo que daba urgencia a la inmediata revisión de tal legislación. Para tal efecto, se dictó el Decreto Ley $\mathrm{N}^{\circ}$ 602, de 7 de agosto de 1974, en donde se faculta al Ministerio de la Vivienda y Urbanismo para suspender la vigencia, derogar, modificar o adicionar de inmediato todas las disposiciones legales o reglamentarias vigentes relativas a construcciones y urbanización, y a instalaciones de agua potable, alcantarillado, gas y electricidad. Fue así que el 18 de diciembre de 1975 se dicta el Decreto Supremo N ${ }^{\circ}$ 458, que aprueba la "Ley General de Urbanismo y Construcciones", publicada el 13 de abril de 1976.

Ahora bien, el Derecho urbanístico integrado aparece claramente en esta ley, que sistematiza todas las técnicas que se venían desarrollando en la legislación anterior, desde la planificación urbana, los límites urbanos, el uso del suelo, la subdivisión y urbanización del suelo, la renovación urbana, las expropiaciones, la construcción y los permisos, inspección, sanciones, etc. Por lo demás, hay una mejora en la técnica legislativa, al utilizar el concepto más amplio de urbanismo en su denominación y al indicar claramente en su artículo $1^{\circ}$ su objeto de regulación: la planificación urbana, la urbanización y la construcción. Además, se indican cada uno de los niveles de acción, que van desde la Ley General, la Ordenanza General y las Normas Técnicas ${ }^{81}$. Su texto se encuentra dividido en cuatro títulos, destinados respectivamente las Disposiciones generales (Título I); De la planificación urbana (Título II); De la construcción (Título III); y De las Viviendas Económicas (Título IV), más un Título final.

Bien se ha destacado que este cuerpo legal asume con mayor decisión la regulación de la planificación urbana, a diferencia de sus predecesoras, que solo hacían una referencia muy general a la materia y luego se remitían a otros cuerpos normativos, como la Ordenanza general o los planes reguladores ${ }^{82}$. Además, se establecieron cuatro niveles de acción respecto de la planificación: nacional, regional, intercomunal y comunal, junto con lo que se indica en cada una de las partes que componen estos planes reguladores (memoria explicativa, ordenanzas y planos), y las materias que pueden regular, aun cuando solo se ha alcanzado una cota de cumplimiento aceptable a nivel comunal e intercomunal.

Por otra parte, ha existido cierta discusión respecto de la naturaleza de este cuerpo legal. Si bien se trata de un decreto supremo, se dictó previa delegación de facultades legislativas conforme con el citado Decreto Ley No 602, de 7 de agosto de 1974, por lo que se trataría de un Decreto con Fuerza de Ley. No obstante lo anterior, se debe tener

\footnotetext{
81 Artículo $2^{\circ}$.

82 Fernández, J., "Historia del Derecho urbanístico chileno", en Revista de Derecho Público, $\mathrm{N}^{\circ} 77$,
} 2012, pp. 91-92. 
presente que con la entrada en vigencia de la Constitución Política de 1980 no es posible la delegación legislativa respecto de materias que comprenden garantías constitucionales (artículo 64 inc. $2^{\circ}$ ), como sería en este caso. Por tanto, si bien este cuerpo legal mantiene su vigencia, a futuro no puede ser modificado o derogado sino por una ley formal.

Este texto legal siguió siendo complementado por la Ordenanza General contenida en el DFL No345 de 1931, hasta su derogación mediante el Decreto Supremo $N^{\circ} 47$, de 5 de junio de 1992, del Ministerio de Vivienda y Urbanismo, que fija el actual texto de la Ordenanza General de la Ley General de Urbanismo y Construcciones.

Por su parte, el DFL N ${ }^{\circ} 458$, de 1976, ha sido objeto de más de una veintena de modificaciones, pero mantiene su vigencia en la parte sustancial. Como se ha dicho, se trata de un cuerpo legal que disciplina los aspectos centrales de la acción urbana en el ámbito de la planificación, la urbanización y la construcción, sin embargo, presenta algunas deficiencias cuyos análisis escapan al objeto de este trabajo, pero que básicamente se traducen en la carencia de mecanismos adecuados de gestión urbana, en los problemas de su implementación mediante instrumentos de planificación territorial que cuenten con un diagnóstico apropiado y oportuno, y la falta de un desarrollo de una política urbana a partir de instrumentos de ordenación supralocal, en la que la ley poco o nada aporta.

\section{CONCLuSiones}

El análisis de las normas urbanísticas que preceden al surgimiento de nuestro actual Derecho urbanístico nos permite comprobar la constante necesidad que ha existido para dictar diversas normas que permitan enmarcar el ejercicio del ius aedificandi como consecuencia de las necesidades que plantea la vida en las urbes, y que obliga a asumirlas por razones de seguridad, higiene, accesos y vivienda, entre otros. A causa de las dimensiones de la ciudad, la reforma interior de las urbes no fue una preocupación en la Antigüedad ni en la Edad Media, ya que el hacinamiento y los problemas sanitarios que generan dichas medidas serán consecuencia del proceso de emigración que se experimenta durante el siglo XIX desde el campo a la ciudad. Es a partir de este momento en que se deben enfrentar los problemas urbanos con mayor urgencia, ya sea mediante una reforma interior de las ciudades o con el ensanche o crecimiento de las urbes.

En nuestro caso, dichas medidas fueron adoptadas paulatinamente en el marco de la policía urbana radicada en las entidades locales, tal cual como venía sucediendo desde el medievo. Sin embargo, la imperiosa necesidad de ordenar la ciudad obligó a la dictación de normas concretas en materia sanitaria y, a partir de las mismas, de reforma interior y ensanche de las ciudades, configurando las primeras técnicas urbanísticas. Es natural que bajo la lógica liberal dicha función se haya encomendado en primer término al legislador. Es la ley la que planifica la ciudad, fija el límite urbano y se ocupa de la altura de los edificios. Sin embargo, lentamente surge la necesidad de utilizar técnicas más intensas que se delegan en los órganos administrativos, particularmente en las municipalidades, mediante la aprobación de un simple plano, el que llegará a convertirse en un instrumento de planificación por medio de los planes reguladores, o la obligación 
del permiso previo para construir, llegando a la imposición de cargas urbanísticas que parten con la expropiación y culminan con las cesiones.

Esto nos permite demostrar las hipótesis formuladas al inicio de esta investigación. En primer lugar, solo constituye normativa urbanística aquella que tiene por objeto la regulación del uso y edificabilidad del suelo en el marco de la creación y desarrollo de las urbes cualquiera sea su finalidad (religiosa, militar, fundación o buen orden de las ciudades). Por tanto, aquellas disposiciones que inciden en la creación y desarrollo del espacio urbano, pero que no tienen este sentido, fundamento o función deben ser calificadas de normas de incidencia urbanística. A su vez, la normativa urbanística en sentido amplio comprende todas las disposiciones que se han dictado durante las diversas etapas de la historia de la humanidad para la creación y orden de la ciudad, mientras que en sentido estricto las normas urbanísticas propiamente dichas o de Derecho urbanístico, responden al fenómeno que se produce a partir de la segunda mitad del siglo XIX y que dan lugar a la existencia de una función pública específica, con instituciones propias, que buscan obtener un orden racional del espacio y la ciudad como respuesta a las necesidades sociales y económicas de una población urbana en crecimiento, y que culmina con el Derecho urbanístico integrado. En este caso, la nueva normativa no constituye una mera limitación al derecho de propiedad, sino que implica la adopción de determinaciones desde la autoridad pública respecto del modelo territorial que se pretenden alcanzar como una función pública que debe cumplir. Al hacer ciudad no estamos frente al ejercicio del derecho de propiedad, sino que ante decisiones públicas que nos indican un modelo de desarrollo urbano, se controla y, en su caso, se sanciona, dejando la facultad de los propietarios como un residuo que emana de los intersticios de las decisiones públicas que debiesen responder al interés común o general.

\section{BIBLIOGRAFÍA}

Aguirre, B. y Castillo, S., Para una comprensión del espacio público urbano en Santiago de Chile: la segunda mitad del siglo XIX y la época del Centenario, Centro de Estudios Arquitectónicos, Urbanísticos y del Paisaje, Universidad Central, Santiago, 2002.

Aguirre, B. y Castillo, S., "El espacio público moderno. Sueños y realidades de Karl Brunner en Santiago de Chile, 1929-1934", en Diseño Urbano y Paisaje, No 3, vol. I, 2005.

Arrieta, B., Estudio Sobre la Ley de Construcciones y Urbanización, Memoria de Prueba para optar el grado de Licenciado en Ciencias Jurídicas y Sociales de la Universidad de Chile, Editorial Jurídica de Chile, Santiago, 1954.

Benevolo L., Los orígenes del urbanismo moderno, Ecleste Ediciones, Madrid, 1996.

Brahm, E., Propiedad sin Libertad. Chile 1925-1973, Universidad de los Andes, Santiago, 1999.

Cortez, A., Sociedad y cultura en Talca, 1910: la provincia y el Centenario Nacional, Consejo Nacional de la Cultura y las Artes, Talca, 2013.

De Ramón, A., "Suburbios y arrabales en un área metropolitana. El caso de Santiago de Chile, 1872-1932”, en HARdoy, J. y SCHAEdel, R. (comp.), Ensayos histórico-sociales sobre la urbanización en América Latina, SIAP, Buenos Aires, 1978.

De Ramón, A. "Santiago de Chile, 1850-1900. Límites urbanos y segregación espacial”, en Revista Paraguaya de Sociología, No 42-43, 1978, pp. 253-276. 
De Ramón, A. "Estudio de una periferia urbana: Santiago de Chile 1850-1900" en Historia, No 20, 1985, pp. 199-289.

De Ramón, A. "Un progreso interrumpido: El caso de Talca durante la segunda mitad del siglo XIX", en EURE, No 62, 1995, pp. 33-47.

De Ramón, A. Santiago de Chile (1541-1991). Historia de una sociedad urbana, Editorial Sudamericana Chilena, Santiago, 2000.

Fernández, J., "Historia del Derecho urbanístico chileno", en Revista de Derecho Público, N $^{\circ} 77$, pp. 79-97, 2012.

Fernández, J. y Holmes, F., Derecho Urbanístico Chileno, Editorial Jurídica de Chile, Santiago, 2008.

García de EnTERría, E., "Dictamen sobre legalidad de ordenanzas municipales sobre el uso del suelo y edificación”, en Revista de Administración Pública, No 50, 1966, pp. 309-335.

GeIsse, G., "Tres momentos históricos en la ciudad hipanoamericana del siglo XX", en EURE, $\mathrm{N}^{\circ} 38,1986$, pp. 8-33.

GuARDA, F., Historia de Valdivia 1552-1952, Imprenta Cultura, 1953.

Gurovich W., A., "Conflictos y negociaciones: La Planificación Urbana en el desarrollo del Gran Santiago, Chile", en Revista de Urbanismo, No 2, 2000, pp. 1-39.

Jans, S., El desarrollo de las ideas socialistas en Chile, Santiago, 1984, consultado en http://www. archivochile.com/Izquierda_chilena/vision_gen/ICHvisiongen0005.pdf

Lorenzo, S., Origen de las ciudades chilenas. Las fundaciones del siglo XVIII, Andrés Bello, Santiago, 1983.

Lorenzo, S. y Urbina Burgos, R., La política de poblaciones en Chile durante el siglo XVIII. El Observador, 1978.

Parejo, L., "Apuntes para una interpretación del sistema legal urbanístico en clave histórica", en Ciudad y Territorio, No 107-108, 1996, pp. 149-166.

Romero, L., "Urbanización y sectores populares: Santiago de Chile, 1830-1875”, en EURE, 31, 1984, pp. 55-66.

Sabatini F. y Soler F., "Paradoja de la planificación urbana en Chile", en EURE, 63, 1995, pp. 61-73.

Salazar, G., "El Municipio Cercenado (La lucha por la autonomía de la asociación municipal en Chile, 1914-1973)", en Salazar, G. y Benítez, J., Autonomía, espacio y gestión del municipio cercenado, Universidad Arcis, Santiago, 1998.

Schmidt, L., Legislación y reglamentación de construcciones y urbanización, Santiago, 1935.

SICA P., Historia del urbanismo moderno. El siglo XX., Instituto de Administración Local, Madrid, 1981.

Sunkel, O., Un siglo de Historia económica de Chile. 1830-1930, Ediciones Cultura Hispánica, 1982.

Urbina, M., Los conventillos de Valparaíso, 1880-1920. Fisonomía y percepción de una vivienda popular urbana, $2^{a}$ edición, Ediciones Universitarias de Valparaíso de la Universidad Católica de Valparaíso, 2011.

Urmeneta, J., Disposiciones legales y municipales para la construcción de edificios, Imprenta Diner, 1915.

VAlenZuela, J., "Estructuración del espacio popular en una ciudad intermedia: Curicó, 18701990 ", en Historia, No 25, 1990, pp. 255-272.

Vicuña Mackenna, B., La transformación de Santiago, Imprenta de la Librería del Mercurio, Santiago, 1872. 